\title{
Creatine supplementation increases soleus muscle creatine content and lowers the insulinogenic index in an animal model of inherited type 2 diabetes
}

\author{
BERT OP'T EIJNDE ${ }^{1}$, HASSAN JIJAKLI ${ }^{2}$, PETER HESPEL ${ }^{1}$ and WILLY J. MALAISSE ${ }^{2}$ \\ ${ }^{1}$ Exercise Physiology and Biomechanics Laboratory, Katholieke Universiteit Leuven, 3001 Leuven; \\ ${ }^{2}$ Laboratory of Experimental Hormonology, Brussels Free University, 1070 Brussels, Belgium
}

Received February 6, 2006; Accepted March 30, 2006

\begin{abstract}
Creatine supplementation may exert beneficial effects on muscle performance and facilitate peripheral glucose disposal in both rats and human subjects. The present study was undertaken to explore the effects of creatine supplementation on the ATP, creatine, phosphocreatine and glycogen content of white and red gastrocnemius and soleus muscles and on blood D-glucose and plasma insulin concentrations before and during an intravenous glucose tolerance test in GotoKakizaki rats, a current animal model of inherited type 2 diabetes mellitus. Creatine supplementation increased muscle creatine content, especially in the soleus muscle of young rats $(+35.5 \pm 15.8 \%$; d.f. $=10 ; \mathrm{p}<0.05)$, and lowered the insulinogenic index, i.e. the paired ratio between plasma insulin and blood D-glucose concentrations. The latter change was mainly attributable to a lowering of plasma insulin concentration. It is proposed, therefore, that creatine supplementation may improve the sensitivity to insulin in extrapancreatic sites in the present animal model of type 2 diabetes.
\end{abstract}

\section{Introduction}

Ever since Hill (1) recognized guanidine-acetate compounds, such as creatine, as a possible tool to study the regulation of glucose homeostasis, many studies have investigated the impact of creatine on carbohydrate metabolism. Creatine intake, commonly used to explore the creatine kinase system in such tissues as skeletal muscle $(2,3)$ and endocrine pancreas (4), increases blood, muscle and pancreas creatine concentration $(4,5)$, and may improve whole body glucose homeostasis $(4,6)$. Theoretically, creatine supplementation could affect tissue

Correspondence to: Professor Willy J. Malaisse, Laboratory of Experimental Hormonology, Brussels Free University, 808 Route de Lennik, B-1070 Brussels, Belgium

E-mail:malaisse@ulb.ac.be

Key words: Goto-Kakizaki rats, creatine supplementation, skeletal muscle, insulinogenic index glucose uptake either by a direct effect on peripheral tissue, e.g. myocytes, or by increasing pancreatic insulin secretion. It was repeatedly shown that short-term creatine intake not only improves muscular functional capacity (7-10), but also increases muscle glycogen content in rats (11) and humans $(6,8,12-14)$. Moreover, oral creatine intake counteracts the inactivity-induced reduction of muscle GLUT4 expression in healthy volunteers, whilst subsequent rehabilitation training increases muscle GLUT4 content $(6,15)$. However, the effect of creatine intake on insulin secretion remains a matter of debate. Whilst supraphysiological concentrations of guanidinoacetate compounds were found to increase insulin output in some early in vitro studies (16-18), more recent in vivo studies conducted in healthy rats as well as in human subjects failed to confirm these findings $(11,14,19-21)$, except for an increase of fasting insulin levels after 4-8 weeks of creatine supplementation in rats (4).

The above described beneficial action of creatine intake on glucose homeostasis has so far only been documented in healthy rodents and human subjects. Considering its potential clinical therapeutic interest in the prevention and/or treatment of type 2 diabetes, the present study is aimed at investigating whether oral creatine supplementation has an impact on whole body glucose disposal during an intravenous glucose tolerance test in Goto-Kakizaki rats, a current animal model of inherited type 2 diabetes (22). Moreover, in order to explore possible age-related differences in the response to creatine supplementation, the experiments were conducted in either 6-week or 14-week old animals.

\section{Materials and methods}

Animals. Male Goto-Kakizaki (GK) rats, obtained from a colony bred at Brussels Free University, were maintained on a 12:12 light-dark cycle at $22^{\circ} \mathrm{C}$. From the start of the study, 6-week $(n=12)$ and 14 -week $(n=12)$ old GK rats were caged individually and allowed, for 8 successive weeks, free access to normal rodent pellets (Kliba Nafag, Kaiseraugust, Switzerland) alone (control group) or enriched with $2 \%(\mathrm{w} / \mathrm{w})$ creatine monohydrate (Creapure $^{\circledR}$, Degussa, Freising, Germany; creatine group). All rats had free access to drinking water. The study protocol was approved by the Ethics Committee for Animal Procedures at K.U. Leuven. 
Study protocol. Following the above described dietary interventions, rats were anaesthetized intraperitoneally with a mixture of ketamine (50 mg $/ \mathrm{kg}^{-1}$; Pfizer, Brussels, Belgium), xylazine (10 mg/kg-1 Bayer, Leverkussen, Germany) and atropine $\left(0.25 \mathrm{mg} / \mathrm{kg}^{-1}\right.$; Sterop Brussels, Belgium) and were prepared surgically for an intravenous glucose tolerance test. Briefly, this involved catheter (Degania Silicone, Degania Bet, Israel) insertion into the left vena jugularis, and tunnelling to an incision in the neck. To avoid clotting, the silicone catheter was filled with heparinized saline before sealing. After an overnight fast (16-18h), a $150 \mu \mathrm{l}$ blood sample was collected from the tail tip in heparinized capillaries. Blood glucose concentration was measured immediately in duplicate. The remainder of the blood sample was rapidly centrifuged $\left(13,000 \mathrm{x} \mathrm{g}\right.$ at $\left.4^{\circ} \mathrm{C}, 3 \mathrm{~min}\right)$ and the supernatant was stored at $-80^{\circ} \mathrm{C}$ for plasma insulin analysis at a later date. Thereafter, conscious rats were injected with $1 \mathrm{~g}$ glucose $/ \mathrm{kg}^{-1}$ body weight using a $30 \%(\mathrm{w} / \mathrm{v})$ D-glucose solution in $0.9 \%(\mathrm{w} / \mathrm{v})$ saline. Following 5, 10, 15, 30, 60, 90 and $120 \mathrm{~min}$, blood samples were collected and processed as described above. After blood sampling, the rats were anaesthetized intravenously using pentobarbital sodium $\left(0.5 \mathrm{mg} / \mathrm{kg}^{-1}\right.$; Nembutal, Brussels, Belgium). The medial superficial part of the gastrocnemius consisting mainly of fast-glycolytic fibers (white gastrocnemius), the soleus consisting mainly of slow-oxidative fibers and a deep part of the medial head of the gastrocnemius consisting mainly of fast-oxidative fibers (red gastocnemius) were dissected from both hind limbs, freed from visible connective tissue and blood, freeze-clamped with aluminium clamps cooled in liquid $\mathrm{N}_{2}$ and stored at $-80^{\circ} \mathrm{C}$ for analysis at a later date. The rats were then sacrificed by pentobarbital sodium overdose.

\section{Measurements}

Food intake and body weight. Following 8 weeks of ad libitum access to the above described rat pellets, residual food was weighed to calculate average daily food intake. Body weight was registered on a weekly basis.

Blood biochemistry. Whole blood glucose concentration was determined in duplicate on an Analox ${ }^{\circledR}$ GM7 glucose analyzer (London, England). Plasma insulin concentration was determined by a double-antibody radio-immunoassay with rat insulin as the standard (Novo Research Institute, Bagsvaerd, Denmark).

Muscle biochemistry. For the biochemical analysis, muscle samples from the right hind limb were freeze-dried for $36 \mathrm{~h}$ at $-50^{\circ} \mathrm{C}$. Muscle glycogen content of the freeze-dried muscle samples $(2-3 \mathrm{mg})$ was determined fluorometrically by a hexokinase method after acid hydrolysis (23). Muscle ATP, free creatine and phosphocreatine concentration was analyzed from perchloric acid precipitated extractions of the freezedried muscle samples $(3-5 \mathrm{mg}$ ) using standard enzymatic fluorometric assays (24). Muscle total creatine content was calculated as the sum of free creatine and phosphocreatine. All data are expressed in $\mathrm{mmol} / \mathrm{kg}^{-1}$ dry weight (wt.).

Stastistical analysis. The insulinogenic index was taken as the paired ratio between plasma insulin and blood glucose

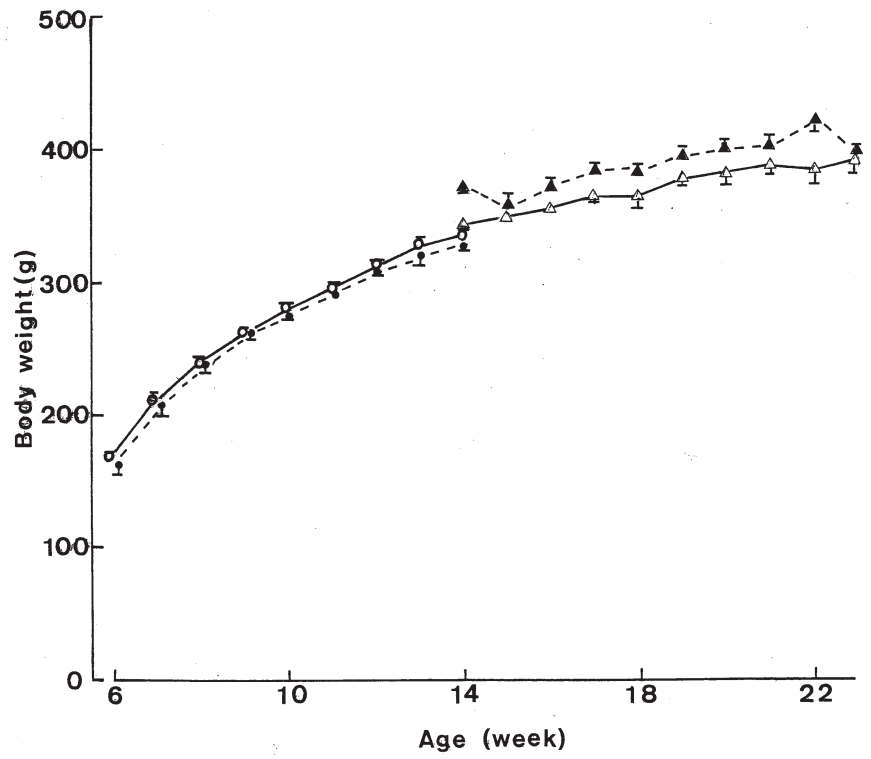

Figure 1. Time course for the changes in body weight of younger (circles) and older (triangles) GK rats fed either a control diet (open symbols and solid lines) or a creatine-supplemented diet (closed symbols and dotted lines). Mean values ( \pm SEM) refer to 6 individual measurements, except on week $13(n=4), 14$ (triangles; $n=2-4), 22$ and $23(n=2-4)$.

concentration. During the intravenous glucose tolerance test, two older creatine-supplemented rats died for an unknown reason. They were excluded from all statistical analyses. All results are expressed as mean values ( \pm SEM). The statistical significance of differences between mean values was assessed, as required, by variance analysis or use of Student's t-test.

\section{Results}

Body weight and food intake. Fig. 1 illustrates the time course for the changes in body weight in the four groups of rats. Over a period of 8 weeks, the gain in body weight was not different ( $P>0.25$ or more) in the control and creatine-supplemented rats (Table I). It was obviously higher $(\mathrm{P}<0.001)$ in the younger rats $(167 \pm 6 \mathrm{~g} ; \mathrm{n}=12)$ than in the older animals $(48 \pm 3 \mathrm{~g} ; \mathrm{n}=12)$.

The daily food intake was not different ( $\mathrm{P}>0.5$ or more) in the control and creatine-supplemented animals (Table I). As expected, however, it was slightly higher $(\mathrm{P}<0.02)$ in the older rats $(25.5 \pm 0.6 \mathrm{~g} /$ day; $\mathrm{n}=6)$ than in the younger animals $(23.4 \pm 0.4 \mathrm{~g} /$ day; $\mathrm{n}=6)$.

Blood D-glucose and plasma insulin concentrations. The basal blood D-glucose concentration, after overnight fasting, was not different in control and creatine-supplemented rats at 14 or 22-23 weeks of age (Table I). It was significantly higher $(\mathrm{P}<0.05)$, however, in the older rats $(8.23 \pm 1.84 \mathrm{mM} ; \mathrm{n}=10)$ than in the younger animals $(4.24 \pm 0.13 \mathrm{mM} ; \mathrm{n}=12)$. Five minutes after the intravenous injection of D-glucose, the increment in blood D-glucose concentration above paired basal value was not significantly different in younger versus older rats and in control versus creatine-supplemented animals, with an overall mean value of $8.42 \pm 0.45 \mathrm{mM}(\mathrm{n}=22)$. Thereafter, the blood D-glucose concentration remained fairly stable, clearly documenting glucose intolerance in the GK rats. Even at $120 \mathrm{~min}$, the paired decrease in blood D-glucose 
concentration below that recorded at 5 min did not exceed $2.21 \pm 0.52 \mathrm{mM}(\mathrm{n}=22)$. In this respect, there was again no significant difference between younger and older rats or control and creatine-supplemented animals (Table I).

The increase in blood D-glucose concentration provoked by the injection of the hexose was not associated with any sizeable increase in plasma insulin concentration. On the contrary and as a rule, the concentration of insulin was somewhat lower after than before exogenous D-glucose administration (Fig. 2). Both before and after such administration, the mean plasma insulin concentration was higher in older than younger rats. Thus, in the latter animals, it averaged $148.1 \pm 11.7 \%(n=36 ; \mathrm{P}<0.001)$ of the corresponding mean values found at the same time during the glucose tolerance test in younger rats fed the same diet $(100.0 \pm 4.5 \%$; $\mathrm{n}=48$ ). The higher plasma insulin concentration found in older compared to younger animals coincided, as already mentioned, with a higher blood D-glucose concentration in the former. In both younger and older rats, the plasma insulin concentration was lower in the creatine-supplemented animals than in the control ones; pooling all available data, it averaged, in the creatine-supplemented animals, 81.2 $\pm 3.4 \% \quad(n=40 ; \mathrm{P}<0.05)$ of the mean corresponding values found at the same time during the glucose tolerance test and at the same age in control rats $(100.0 \pm 7.5 \% ; n=44)$. When considering young and older rats on a separate basis, such a difference remained significant $(\mathrm{P}<0.025)$ only in the younger animals. Nevertheless, the percentage found in the creatine-supplemented animals was not significantly different $(\mathrm{P}>0.5)$ in young rats $(79.3 \pm 4.4 \%$; $\mathrm{n}=24)$ and older rats $(83.9 \pm 5.4 \% ; \mathrm{n}=16)$, both of these values being significantly lower $(\mathrm{P}<0.01$ or less) than unity.

Insulinogenic index. The finding that creatine supplementation lowers the plasma insulin, but not blood D-glucose, concentration could suggest improved sensitivity to insulin in extrapancreatic site(s). This consideration led us to establish the insulinogenic index, i.e. the paired ratio between plasma insulin and blood D-glucose concentrations.

The insulinogenic index was lower in the creatinesupplemented GK rats than in the control animals (Fig. 3, middle panel). The relative magnitude of such a decrease was not significantly different (d.f. $=38 ; \mathrm{P}>0.2)$ in the animals examined at the age of either 14 or 23 weeks. Thus, relative to the mean values found at the same time(s) during the glucose

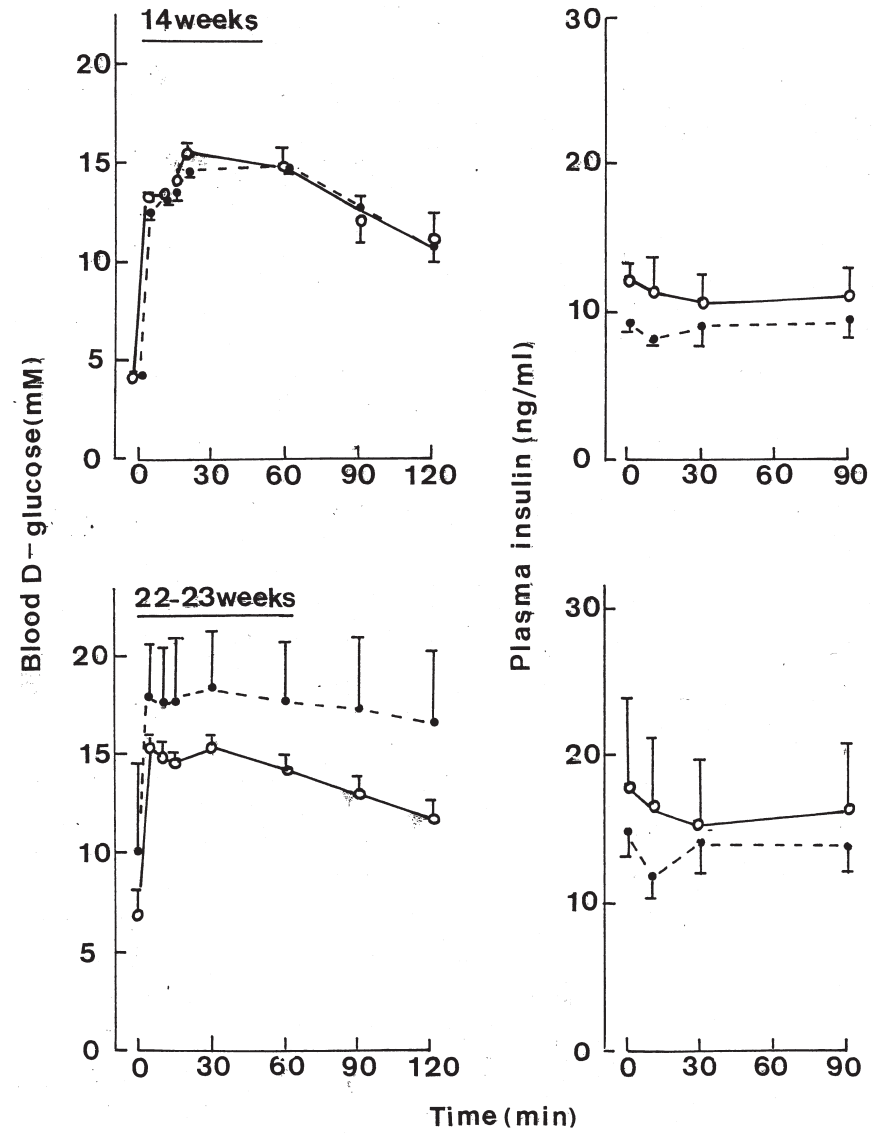

Figure 2. Time course for the changes in blood D-glucose (left) and insulin (right) concentrations during an intravenous glucose tolerance test in control (open circles and solid lines) and creatine-supplemented (closed circles and dotted lines) GK rats examined at 14 (upper panels) or 22-23 (lower panels) weeks of age. Mean values $( \pm$ SEM) refer to 4-6 individual experiments.

tolerance test in the control animals, the measurements made in the creatine-supplemented rats averaged, at the 14th and 22nd and 23rd week, $77.9 \pm 4.7 \%(n=24)$ and $68.3 \pm 6.3 \%(n=16)$, respectively. Pooling all available data, the insulinogenic index averaged, in the creatine-supplemented rats, $74.2 \pm 3.8 \%$ $(\mathrm{n}=40 ; \mathrm{P}<0.01)$ of the mean corresponding control values $(100.0 \pm 8.6 \% ; n=44)$. It should be emphasized that, relative to the mean value found at the same age in the control rats, the insulinogenic index measured in the creatine-supplemented

Table I. Body weight change, food intake and blood D-glucose concentration.

\begin{tabular}{|c|c|c|c|c|}
\hline \multirow{2}{*}{$\begin{array}{l}\text { Age (weeks) } \\
\text { Diet }\end{array}$} & \multicolumn{2}{|c|}{14} & \multicolumn{2}{|c|}{$22-23$} \\
\hline & Control & Creatine & Control & Creatine \\
\hline Body wt. gain (g/8 weeks) & $169 \pm 11(6)$ & $165 \pm 4(6)$ & $44 \pm 6(6)$ & $51 \pm 2(6)$ \\
\hline Food intake (g/day) & $23.1 \pm 0.9(3)$ & $23.7 \pm 0.4(3)$ & $25.4 \pm 1.2(3)$ & $25.6 \pm 0.4(3)$ \\
\hline \multicolumn{5}{|l|}{ Blood D-glucose (mM) } \\
\hline basal & $4.19 \pm 0.22(6)$ & $4.28 \pm 0.18(6)$ & $6.97 \pm 1.31(6)$ & $10.11 \pm 4.44(4)$ \\
\hline$\Delta(\min 5-\min 0)$ & $9.02 \pm 0.41(6)$ & $8.23 \pm 0.42(6)$ & $8.41 \pm 1.10(6)$ & $7.82 \pm 1.89(4)$ \\
\hline$\Delta(\min 5-\min 120)$ & $1.93 \pm 1.30(6)$ & $1.71 \pm 0.91(6)$ & $3.59 \pm 0.72(6)$ & $1.29 \pm 1.22(4)$ \\
\hline
\end{tabular}



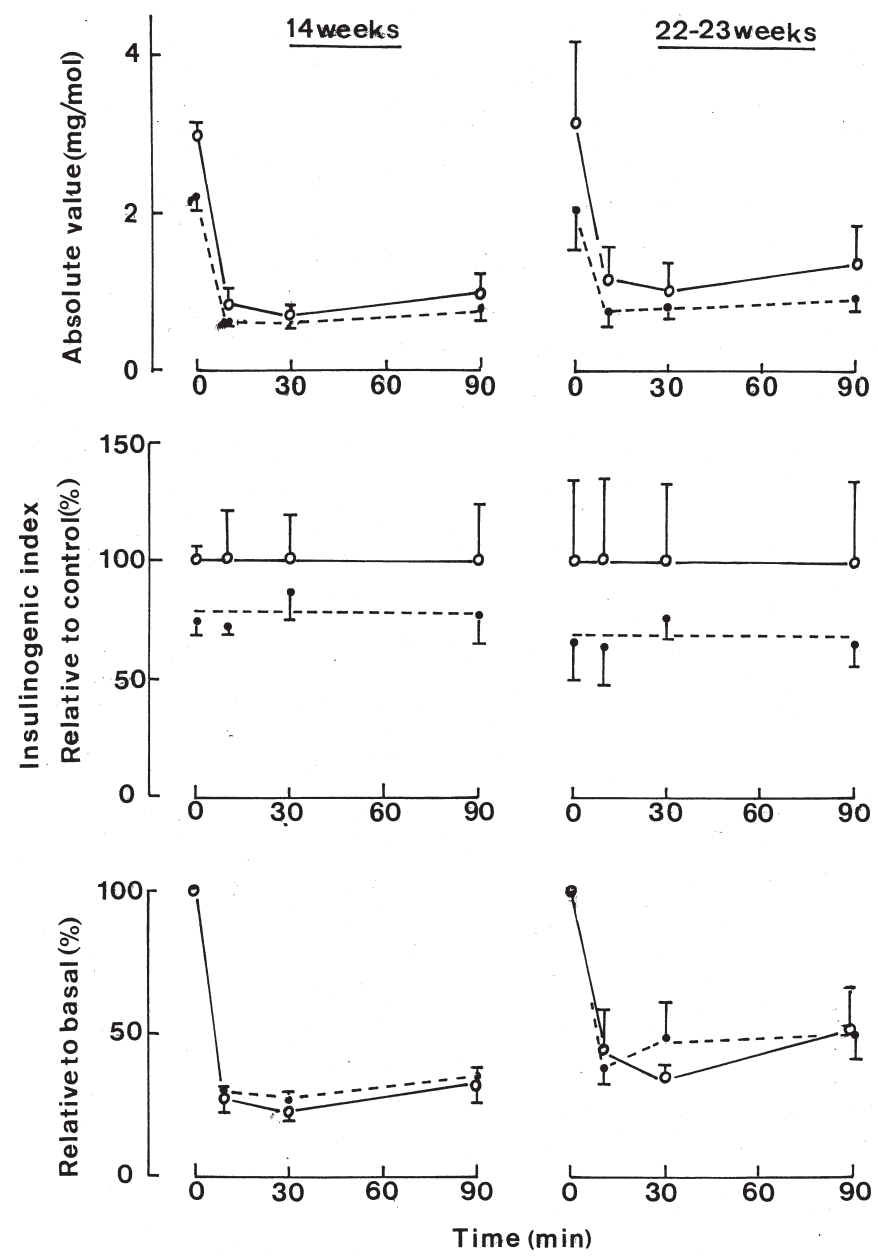

Figure 3. Time course for changes in the insulinogenic index during an intravenous glucose tolerance test in control (open circles and solid lines) and creatine-supplemented (closed circles and dotted lines) GK rats examined at 14 (left) or 22-23 (right) weeks of age. Mean values ( \pm SEM) refer to 4-6 individual determinations and are expressed in absolute terms (upper panels), relative to the mean value found at the same time in control rats (middle panels) or relative to the paired basal value (lower panels).

rats was not significantly different (d.f. $=38 ; \mathrm{P}>0.6)$ before exogenous D-glucose administration $(70.7 \pm 7.1 \% ; \mathrm{n}=10)$ and at identical time(s) thereafter $(75.2 \pm 4.5 \% ; \mathrm{n}=30)$.

The administration of D-glucose always caused a dramatic decrease in the insulinogenic index (Fig. 3, upper panel). The relative magnitude of such a glucose-induced decrease in the insulinogenic index was not significantly different in control rats and creatine-supplemented animals (Fig. 3, lower panel).

When comparing the rats examined at 14 and 22-23 weeks of age, the relative magnitude of the glucose-induced decrease in the insulinogenic index was, at each time of the test, more pronounced in the younger rats than in the older animals (Fig. 3, lower panel). Thus, relative to paired basal value, the insulinogenic index recorded after intravenous injection of D-glucose averaged $44.7 \pm 4.4 \%(n=27)$ in the 22- to 23 -week old rats, compared to $(\mathrm{P}<0.001)$ only $29.2 \pm 1.8 \%(\mathrm{n}=36)$ in the 14 -week old animals. When compared at the same time of the test $(10,30$ and $90 \mathrm{~min})$, the mean percentage reached in the younger rats only represented $65.4 \pm 3.7 \%(\mathrm{n}=36 ; \mathrm{P}<0.001)$ of that recorded in the older animals $(100.0 \pm 9.6 \% ; \mathrm{n}=27)$.

This coincided, however, with the fact already mentioned that the mean basal blood D-glucose concentration was lower

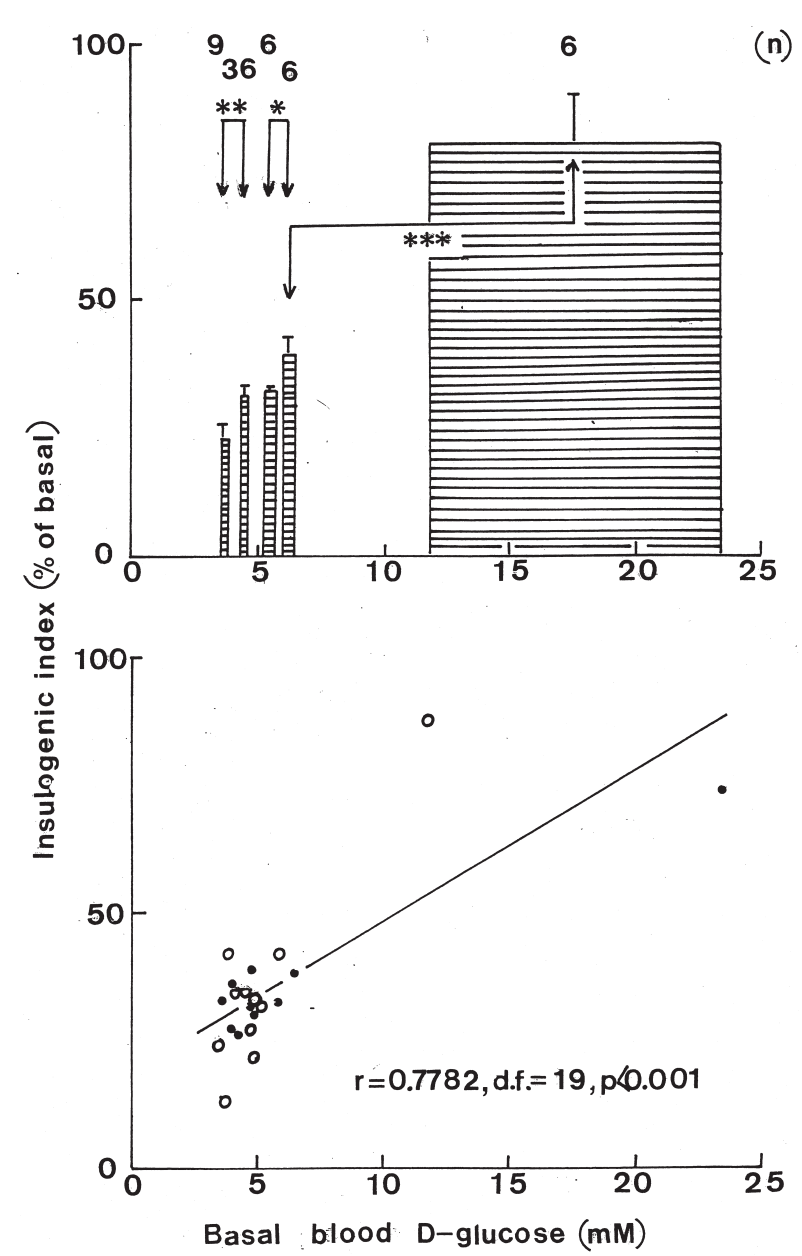

Figure 4. Relationship between the insulinogenic index measured after intravenous administration of D-glucose and expressed relative to paired basal value and basal blood D-glucose concentration in GK rats. In the upper panels, mean values $( \pm$ SEM) refer to 6-36 measurements $(n)$ of insulinogenic index made in groups of 2-12 rats in the indicated range of basal blood D-glucose concentrations, asterisks indicate statistical significance $\left({ }^{*} \mathrm{P}<0.06 ;{ }^{* *} \mathrm{P}<0.025 ;{ }^{* * *} \mathrm{P}<0.005\right)$ of differences between mean values. The lower panel refers to the correlation between the two variables in control (open circles) and creatine-supplemented (closed circles) GK rats, each individual value for the insulinogenic index representing the mean of the measurements made at min 10,30 and 90 of the intravenous glucose tolerance test.

$(\mathrm{P}<0.05)$ in the 14 -week old rats $(4.24 \pm 0.13 \mathrm{mM} ; \mathrm{n}=12)$ than in the animals examined at the age of $22-23$ weeks, whether considering all of the latter animals $(8.23 \pm 1.84 \mathrm{mM} ; \mathrm{n}=10)$ or only those in which the plasma insulin concentration was measured $(8.11 \pm 2.05 \mathrm{mM} ; \mathrm{n}=9)$. There was indeed a highly significant correlation $(\mathrm{r}=0.7782 ; \mathrm{n}=21 ; \mathrm{P}<0.001)$ between the individual measurements of basal blood D-glucose concentration and the corresponding mean value for the insulinogenic index recorded after administration of exogenous D-glucose and expressed relative to paired basal value (Fig. 4, lower panel). The upper panel of Fig. 4 illustrates the progressive increase in the mean values for the insulinogenic index measured after administration of D-glucose and expressed relative to paired basal value as a function of the basal plasma D-glucose concentration. It reveals that such an increase already achieved statistical significance in the lowest range of basal plasma D-glucose concentrations recorded in the present study. 
Table II. Muscle biochemistry.

\begin{tabular}{|c|c|c|c|c|}
\hline \multirow{2}{*}{$\begin{array}{l}\text { Age (weeks) } \\
\text { Diet }\end{array}$} & \multicolumn{2}{|c|}{14} & \multicolumn{2}{|c|}{$22-23$} \\
\hline & Control & Creatine & Control & Creatine \\
\hline \multicolumn{5}{|c|}{ ATP content (mmol/ $/ \mathrm{kg}^{-1}$ dry wt.) } \\
\hline White gastrocnemius & $28.6 \pm 1.0(5)$ & $27.0 \pm 3.5(6)$ & $26.1 \pm 2.0(5)$ & $27.1 \pm 1.8(4)$ \\
\hline Red gastrocnemius & $27.5 \pm 1.4(6)$ & $28.4 \pm 1.8(5)$ & $24.6 \pm 2.1(6)$ & $27.8 \pm 1.9(4)$ \\
\hline Soleus & $20.1 \pm 1.5(6)$ & $21.9 \pm 3.0(6)$ & $18.7 \pm 1.0(6)$ & $16.2 \pm 1.2(4)$ \\
\hline \multicolumn{5}{|c|}{ Creatine content (mmol $/ \mathrm{kg}^{-1}$ dry wt.) } \\
\hline White gastrocnemius & $33.7 \pm 3.1(6)$ & $42.8 \pm 4.3(6)$ & $49.9 \pm 3.4(6)$ & $47.5 \pm 6.9(4)$ \\
\hline Red gastrocnemius & $38.7 \pm 2.6(6)$ & $42.9 \pm 7.4(6)$ & $48.5 \pm 4.7(6)$ & $53.8 \pm 3.6(4)$ \\
\hline Soleus & $32.3 \pm 1.6(6)$ & $43.7 \pm 4.8(6)$ & $42.6 \pm 3.8(6)$ & $44.3 \pm 2.5(4)$ \\
\hline \multicolumn{5}{|c|}{ Phosphocreatine content (mmol/ $\mathrm{kg}^{-1}$ dry wt.) } \\
\hline White gastrocnemius & $117.3 \pm 5.6(5)$ & $112.0 \pm 11.0(6)$ & $95.5 \pm 10.9(5)$ & $110.3 \pm 11.6(4)$ \\
\hline Red gastrocnemius & $89.1 \pm 5.4(6)$ & $85.7 \pm 13.1(5)$ & $99.0 \pm 7.5(6)$ & $99.6 \pm 1.5(4)$ \\
\hline Soleus & $70.9 \pm 2.9(6)$ & $71.0 \pm 10.7(6)$ & $59.1 \pm 2.7(6)$ & $65.4 \pm 5.9(4)$ \\
\hline \multicolumn{5}{|c|}{ Total creatine content (mmol $/ \mathrm{kg}^{-1}$ dry wt.) } \\
\hline White gastrocnemius & $148.5 \pm 5.7(5)$ & $154.8 \pm 10.9(6)$ & $145.7 \pm 9.7(5)$ & $157.8 \pm 12.3(4)$ \\
\hline Red gastrocnemius & $127.8 \pm 6.3(6)$ & $131.1 \pm 15.3(5)$ & $147.4 \pm 10.4(6)$ & $153.4 \pm 4.0(4)$ \\
\hline Soleus & $103.2 \pm 2.8(6)$ & $114.7 \pm 9.6(6)$ & $101.6 \pm 5.5(6)$ & $109.7 \pm 7.9(4)$ \\
\hline \multicolumn{5}{|c|}{ Phosphocreatine/creatine ratio } \\
\hline White gastrocnemius & $3.85 \pm 0.38(5)$ & $2.74 \pm 0.32(6)$ & $1.99 \pm 0.29(5)$ & $2.52 \pm 0.52(4)$ \\
\hline Red gastrocnemius & $2.36 \pm 0.19(6)$ & $2.25 \pm 0.52(5)$ & $2.11 \pm 0.24(6)$ & $1.88 \pm 0.14(4)$ \\
\hline Soleus & $2.23 \pm 0.16(6)$ & $1.76 \pm 0.28(6)$ & $1.44 \pm 0.14(6)$ & $1.47 \pm 0.09(4)$ \\
\hline \multicolumn{5}{|c|}{ Glycogen content (mmol of glucose residue $/ \mathrm{kg}^{-1}$ dry wt.) } \\
\hline White gastrocnemius & $132.3 \pm 8.8(6)$ & $136.0 \pm 12.2(6)$ & $146.5 \pm 8.8(6)$ & $145.4 \pm 5.2(4)$ \\
\hline Red gastrocnemius & $141.8 \pm 17.7(6)$ & $109.7 \pm 11.2(6)$ & $150.5 \pm 7.4(6)$ & $138.5 \pm 6.2(4)$ \\
\hline Soleus & $88.6 \pm 7.4(6)$ & $86.3 \pm 10.7(6)$ & $134.8 \pm 9.0(6)$ & $123.9 \pm 4.1(4)$ \\
\hline
\end{tabular}

Muscle biochemistry. Table II summarizes the data relative to muscle biochemistry. The mean values for ATP, phosphocreatine and total creatine content, paired phosphocreatine/ creatine ratio and glycogen content were always lower in the soleus muscle than in the gastrocnemius muscles. Pooling all available data, the ATP content, phosphocreatine and total creatine content, paired phosphocreatine/creatine ratio and glycogen content of the soleus muscle averaged $72.1 \pm 2.9 \%$, $66.1 \pm 2.6 \%, 73.6 \pm 2.2 \%, 71.4 \pm 3.4 \%$ and $78.3 \pm 4.0 \% \quad(n=22$ in all cases), respectively, of the mean paired values $(100.0 \pm 1.4 \%$; $\mathrm{n}=41 ; 100.0 \pm 2.5 \%, \mathrm{n}=41 ; 100.0 \pm 1.8 \%, \mathrm{n}=41 ; 100.0 \pm 3.5 \%$, $\mathrm{n}=41$; and $100.0 \pm 1.4 \%, \mathrm{n}=44$ ) found in the two gastrocnemius muscles (Fig. 5). Such differences were all highly significant $(\mathrm{P}<0.001)$. For these five percentages, there was, as a rule, no significant difference in the soleus muscle of younger versus older rats or control versus creatine-supplemented animals. Only the mean percentage concerning the glycogen content of the soleus muscle was higher $(\mathrm{P}<0.01)$ in the older rats $(89.7 \pm 3.4 \% ; n=10)$ than in the younger animals $(68.8 \pm 5.5 \%$; $\mathrm{n}=12$ ). There was no significant difference, in terms of ATP or glycogen content between white and red gastrocnemius muscles. The phosphocreatine content, total creatine content and paired phosphocreatine/creatine ratio, however, were somewhat higher $(\mathrm{P}<0.02$ or less $)$ in the white than red gastrocnemius muscle. Thus, as judged from the above mentioned values, the phosphocreatine content, total creatine content and paired phosphocreatine/creatine ratio averaged in the white gastrocnemius muscle respectively $107.1 \pm 3.3,104.3 \pm 2.4$ and $109.5 \pm 4.7 \%$ ( $n=20$ in all cases), compared to $93.2 \pm 3.1$, $95.9 \pm 2.3$ and $91.0 \pm 4.5 \%(n=21$ in all cases $)$ in the red gastrocnemius muscle.

The non-phosphorylated creatine content of the soleus muscle averaged $92.9 \pm 3.8 \%(n=22)$ of the mean paired value measured in the two gastrocnemius muscles $(100.0 \pm 2.4 \%$; $\mathrm{n}=44)$. These two percentages were not significantly different from one another $(\mathrm{P}>0.1)$. Likewise, as judged from the same normalized data, the creatine content of the white gastrocnemius $(98.0 \pm 3.4 \%$; $n=22)$ was not significantly different $(\mathrm{P}>0.4)$ to that of the red gastrocnemius $(102.0 \pm 3.4 \% ; n=22)$.

Two obvious age-related differences in muscle biochemistry consisted of the increase $(\mathrm{P}<0.001)$ in the soleus glycogen content from $87.4 \pm 6.2 \mathrm{nmol} / \mathrm{kg}^{-1}(\mathrm{n}=12)$ in the 14 -week old rats to $130.4 \pm 5.7 \mathrm{nmol} / \mathrm{kg}^{-1}(\mathrm{n}=10)$ in the 22 - to 23 -week old rats, and the decrease $(\mathrm{P}<0.02)$ in the soleus phosphocreatine/ 


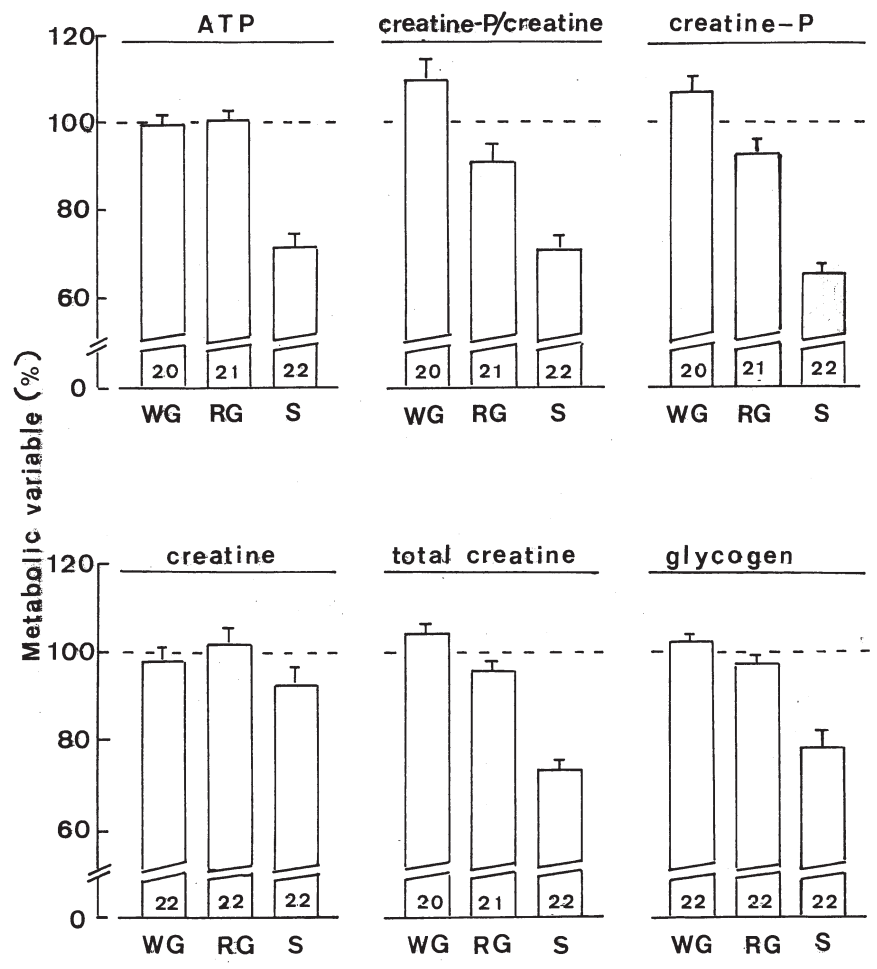

Figure 5. Mean values $( \pm$ SEM) for metabolic variables in white gastrocnemius (WG), red gastrocnemius (RG) and soleus (S) muscles of GK rats refer to the number of individual determinations indicated at the bottom of each column and are expressed relative to the mean value found in each animal in the white and/or red gastrocnemius muscle(s).

creatine paired ratio from $1.99 \pm 0.17(n=12)$ in the younger rats to $1.45 \pm 0.09(n=10)$ in the older animals. This coincided with a trend towards an age-related decrease in the soleus ATP content from $21.0 \pm 1.6$ to $17.7 \pm 0.8 \mathrm{nmol} / \mathrm{kg}^{-1}$ dry wt in the same animals $(\mathrm{P}<0.1)$. In the gastrocnemius muscles, no significant age-related change was observed in terms of the ATP content, paired phosphocreatine/creatine ratio or glycogen content. The creatine content, however, was higher $(\mathrm{P}<0.001)$ in the older than younger rats, averaging in the former case $129.4 \pm 6.3 \%(n=20)$ of the mean corresponding value found in the same type of gastrocnemius muscle of young rats fed the same diet $(100.0 \pm 5.3 \% ; n=24)$. This coincided, in the red gastrocnemius muscle but not in the white gastrocnemius muscle, with a significantly higher total creatine content in older than younger rats. Thus, in the red gastrocnemius muscle of older rats, the total creatine content averaged $116.0 \pm 4.8 \%$ $(\mathrm{n}=10 ; \mathrm{P}<0.05)$ of the mean corresponding value found in younger rats fed the same diet $(100.0 \pm 5.6 \% ; n=11)$.

As a rule, there was no significant difference in the variables of muscle biochemistry between control and creatinesupplemented animals. Nevertheless, the creatine content of the muscles averaged, in the creatine-supplemented rats, $116.1 \pm 6.0 \%(n=30 ; P<0.02)$ of the mean values found at the same age in the same type of muscle(s) of control rats $(100.0 \pm 3.0 \% ; n=36)$. Such a difference was most obvious in the young creatine-supplemented rats, in which the creatine content averaged $124.5 \pm 8.9 \%(\mathrm{n}=18 ; \mathrm{P}<0.02)$ of the mean values found in the same type of muscle(s) of young control rats $(100.0 \pm 3.9 \% ; n=18)$. It should be mentioned, however, that when considering separately each muscle at each age, a significant increase of the creatine content by $35.5 \pm 15.8 \%$ (d.f. $=10 ; \mathrm{P}<0.05$ ) was only recorded in the soleus muscle of young rats. The mean total creatine content (creatine + phosphocreatine) of the muscles from creatine-supplemented rats averaged $106.5 \pm 3.3 \%(n=29)$ of the mean corresponding values found in the same types of muscle(s) obtained from control animals of the same age $(100.0 \pm 2.0 \% ; n=34)$. The latter difference failed, however, to achieve statistical significance $(\mathrm{P}<0.1)$.

\section{Discussion}

The present study investigates the potential beneficial effect of creatine intake on the regulation of whole body glucose homeostasis in spontaneously insulin-resistant Goto-Kakizaki rats and draws attention to three distinct series of findings.

First, it extends to GK rats the knowledge that creatine supplementation increases the creatine content of skeletal muscle $(11,25)$. This increase was quite obvious $(\mathrm{P}<0.02)$ in younger GK rats (14 weeks of age) and failed to achieve statistical significance in older animals (22-23 weeks of age). In relative terms and in line with our earlier findings $(8,11)$, it was most marked in the slow oxidative soleus muscle. Thus, pooling the results obtained in younger and older GK rats, the creatine content of the soleus from creatine-supplemented animals averaged $123.0 \pm 10.3 \%(\mathrm{n}=10 ; \mathrm{P}<0.05)$ of that found at the same age in control rats $(100.0 \pm 4.8 \% ; n=12)$. In the case of the fast glycolytic white and fast oxidative red gastrocnemius muscles, however, the value found in the creatinesupplemented rats $(112.7 \pm 7.5 \% ; n=20)$ failed to be significantly higher $(\mathrm{P}>0.1)$ than that found at the same age in the control animals $(100.0 \pm 3.8 \% ; n=24)$. In the present work, creatine supplementation was continued for 8 weeks because acute creatine intake was found not to alter glucose tolerance or insulin sensitivity (20). Our current findings are compatible with the literature data indicating that a higher level of muscle total creatine content established by acute creatine intake is not maintained upon prolonged supplementation (26).

Second, it reveals that creatine supplementation lowers the insulinogenic index in GK rats. This decrease was observed in both younger and older animals and both before and after administration of exogenous D-glucose (Fig. 3). It was mainly attributable to a lowering of the plasma insulin concentration. These findings suggest, therefore, that creatine supplementation increased the sensitivity to insulin at extrapancreatic sites, possibly including skeletal muscles. However, contradicting the beneficial effect of creatine on muscular insulin sensitivity is the observation that dietary creatine administration did not alter muscle glycogen content, either in young or older rats. As in a prior study conducted in normal rats (11), there was no indication that creatine supplementation improved the secretory behaviour of insulin-producing cells in this animal model of inherited type 2 diabetes.

Finally, the measurements of blood D-glucose and plasma insulin concentration made in the intravenous glucose tolerance test indicated that the severe intolerance to sugar found in GK rats coincided with a paradoxical decrease in plasma insulin concentration and insulinogenic index. Such a paradoxical secretory response of insulin-producing cells in response to 
provoked hyperglycemia, which was already documented in the isolated perfused pancreas of GK rats $(27,28)$, is currently considered as one of the two typical features of the phenomenon of so-called B-cell glucotoxicity or incompetence (29). In this respect, the following considerations should be emphasized.

The relationship illustrated in Fig. 4 between basal plasma D-glucose concentration and the relative magnitude of this glucose-induced paired decrease in the insulinogenic index during the intravenous glucose tolerance test reinforces the view that the paradoxical lowering of such an index, as provoked by the administration of exogenous D-glucose, may be attributable to the interference of the rise in glycemia, following the injection of the hexose, with the catabolism of endogenous nutrients in the insulin-producing cells, such as a decrease in the rate of glycogenolysis $(30,31)$. It may indeed be expected that such a rate is already lower in severely hyperglycemic, as compared to close-to-normoglycemic, rats before the administration of exogenous D-glucose and, hence, less susceptible to a further decrease in response to the rise in glycemia provoked by the injection of the hexose in the former, as compared to the latter, animals. This is not to deny that the extent of glycogen accumulation in insulin-producing cells is probably related to the severity and duration of the perturbation in glucose homeostasis before the injection of exogenous Dglucose, as documented in prior studies $(32,33)$.

It should also be kept in mind that, in overnight fasted rats, the increase in the rate of exogenous D-glucose utilization in islet B-cells is lower than in fed animals (34). Since such a fasting-induced change in D-glucose catabolism, as resulting mainly from the change in activity of key glycolytic enzymes (35), appears attributable to the lowering of plasma D-glucose concentration during starvation, it may also be expected to be most pronounced in rats with the lowest basal glycemia. This would then, in turn, also contribute to a lower insulin response during the glucose tolerance test in these rats, as compared to animals that remained frankly hyperglycemic, even after overnight fasting.

In conclusion, the present study reinforces the concept that the secretory responsiveness of insulin-producing B-cells to a hyperglycemic challenge is modulated, in the present animal model of type 2 diabetes, by the preceding glycemic status. It also reveals that creatine supplementation lowers the insulinogenic index in GK rats, both before and after the administration of exogenous D-glucose. In the light of prior findings $(6,21)$, this may well correspond with the improvement of insulin sensitivity in extrapancreatic targets, e.g. muscle, resulting from the administration of creatine in diabetic GK rats.

\section{Acknowledgements}

We are grateful to M. Mahy and M. Ramaekers for their skilled technical assistance and C. Demesmaeker for secretarial help. This study was supported by grants from Onderzoeksraad K.U.-Leuven (grant OT99/38), Fonds voor Wetenschappelijk Onderzoek Vlaanderen (FWO-Vlaanderen grant G.0255.01) and Belgian Foundation for Scientific Medical Research (grant 3.4517.02). B.E.O. was a Research Fellow of the Onderzoeksraad K.U. Leuven (grant OT99/38).

\section{References}

1. Hill RM: The effect of the administration of creatine on the blood sugar. J Biol Chem 78: iv, 1928.

2. Terjung RL, Clarkson P, Eichner ER, Greenhaff PL, Hespel PJ, Israel RG, Kraemer WJ, Meyer RA, Spriet LL, Tarnopolsky MA, Wagenmakers AJ and Williams MH: American College of Sports Medicine roundtable. The physiological and health effects of oral creatine supplementation. Med Sci Sports Exerc 32: 706-717, 2000.

3. Wyss $\mathrm{M}$ and Kaddurah-Daouk R: Creatine and creatinine metabolism. Physiol Rev 80: 1107-1213, 2000.

4. Rooney K, Bryson J, Phuyal J, Denyer G, Caterson I, and Thompson C: Creatine supplementation alters insulin secretion and glucose homeostasis in vivo. Metabolism 51: 518-522, 2002.

5. Harris RC, Söderlund K and Hultman E: Elevation of creatine in resting and exercised muscle of normal subjects by creatine supplementation. Clin Sci 83: 367-374, 1992.

6. Derave W, Eijnde BO, Verbessem P, Ramaekers M, Van Leemputte M, Richter EA and Hespel P: Combined creatine and protein supplementation in conjunction with resistance training promotes muscle GLUT-4 content and glucose tolerance in humans. J Appl Physiol 94: 1910-1916, 2003.

7. Balsom PD, Ekblom B, Söderlund K, Sjödin B and Hultman E: Creatine supplementation and dynamic high-intensity intermittent exercise. Scand J Med Sci Sports 3: 143-149, 1993.

8. Hespel P, Op't Eijnde B, Van Leemputte M, Urso B, Greenhaff PL, Labarque V, Dynmarkowski S, Van Hecke P, and Richter EA: Oral creatine supplementation facilitates the rehabilitation of disuse atrophy and alters the expression of muscle myogenic factors in humans. J Physiol 536: 625-633, 2001.

9. Hultman E, Söderlund K, Timmons JA, Cederblad G and Greenhaff PL: Muscle creatine loading in men. J Appl Physiol 81: 232-237, 1996.

10. Vandenberghe K, Goris M, Van Hecke P, Van Leemputte M, Van Gerven L and Hespel P: Long-term creatine intake is beneficial to muscle performance during resistance training. J Appl Physiol 83: 2055-2063, 1997.

11. Op't Eijnde B, Richter EA, Henquin J-C, Kiens B and Hespel P: Effect of creatine supplementation on creatine and glycogen content in rat skeletal muscle. Acta Physiol Scand 171: 169-176, 2001.

12. Green AL, Sewell D, Simpson L, Hultman E, MacDonald IA and Greenhaff PL: Creatine ingestion augments muscle creatine uptake and glycogen synthesis during carbohydrate feeding in man. J Physiol 491: 63-64, 1996.

13. Nelson AG, Arnall DA, Kokkonen J, Day R and Evans J: Muscle glycogen supercompensation is enhanced by prior creatine supplementation. Med Sci Sports Exerc 33: 1096-1100, 2001.

14. Robinson TM, Sewell DA, Hultman E and Greenhaff PL: Role of submaximal exercise in promoting creatine and glycogen accumulation in human skeletal muscle. J Appl Physiol 87: 598-604, 1999.

15. Op't Eijnde B, Ursø B, Richter EA, Greenhaff PL and Hespel P: Effect of oral creatine supplementation on human muscle GLUT4 protein content after immobilization. Diabetes 50: 18-23, 2001.

16. Alsever RN, Georg RH and Sussman KE: Stimulation of insulin secretion by guanidinoacetic acid and other guanidine derivatives. Endocrinology 86: 332-336, 1970.

17. Gempel K, Brdiczka D, Kaddurah-Daouk R, Wallimann T, Kaufhold P and Gerbitz KD: The creatine analogue cyclocreatine increases insulin secretion in INS-1 cells via a $\mathrm{K}^{+}$ channel independent mechanism. Diabetologia 39 (suppl 1): A31, 1996.

18. Marco J, Calle C, Hedo JA and Villanueva ML: Glucagonreleasing activity of guanidine compounds in mouse pancreatic islets. FEBS Letters 64: 52-54, 1976.

19. Green AL, Simpson EJ, Littlewood JJ, MacDonald IA and Greenhaff PL: Carbohydrate ingestion augments creatine retention during creatine feeding in man. Acta Physiol Scand 158: 195-202, 1996.

20. Newman JE, Hargreaves M, Garnham A and Snow RJ: Effect of creatine ingestion on glucose tolerance and insulin sensitivity in men. Med Sci Sports Exerc 35: 69-74, 2003.

21. Rooney KB, Bryson JM, Digney AL, Rae CD and Thompson CH: Creatine supplementation affects glucose homeostasis but not insulin secretion in humans. Ann Nutr Metab 47: 11-15, 2003. 
22. Giroix M-H, Sener A, Bailbe D, Leclercq-Meyer V, Portha B and Malaisse WJ: Metabolic, ionic and secretory response to D-glucose in islets from rats with acquired or inherited noninsulin-dependent diabetes. Biochem Med Metab Biol 50: 301$321,1993$.

23. Lowry OH and Passoneau JV: A Flexible System of Enzymatic Analysis. Academic: New York, 1972.

24. Bergmeyer HU: Methods of Enzymatic Analysis. VCH Verlagsgesellschaft, Weinheim, 1985.

25. Eijnde BO, Lebacq J, Ramaekers M and Hespel P: Effect of muscle creatine content manipulation on contractile properties in mouse muscles. Muscle Nerve 29: 428-435, 2004.

26. Derave W, Eijnde BO and Hespel P: Creatine supplementation in health and disease: what is the evidence for long-term efficacy? Mol Cell Biochem 244: 49-55, 2003.

27. Östenson C-G, Khan A, Abdel-Halim SM, Guenifi A, Suzuki K, Goto Y and Efendic S: Abnormal insulin secretion and glucose metabolism in pancreatic islets from the spontaneously diabetic GK rats. Diabetologia 36: 3-8, 1993.

28. Portha B, Serradas P, Bailbé D, Suzuki K-I, Goto Y and Giroix M-H: $\beta$-cell insensitivity to glucose in the GK rat, a spontaneous nonobese model for type II diabetes. Diabetes 40: 486-491, 1991.
29. Malaisse WJ: The anomeric malaise: a manifestation of B-cell glucotoxicity. Horm Metab Res 23: 307-311, 1991.

30. Malaisse WJ, Magetto C, Leclercq-Meyer V and Sener A: Interference of glycogenolysis with glycolysis in pancreatic islets from glucose-infused rats. J Clin Invest 91: 432-436, 1993.

31. Malaisse WJ, Marynissen G and Sener A: Possible role of glycogen accumulation in B-cell glucotoxicity. Metabolism 41: 814-819, 1992.

32. Malaisse WJ, Sener A, Koser M, Ravazzola M and MalaisseLagae F: The stimulus-secretion coupling of glucose-induced insulin release. Insulin release due to glycogenolysis in glucosedeprived islets. Biochem J 164: 447-454, 1977.

33. Marynissen G, Leclercq-Meyer V, Sener A and Malaisse WJ: Perturbation of pancreatic islet function in glucose-infused rats. Metabolism 39: 87-95, 1990.

34. Levy J, Herchuelz A, Sener A and Malaisse WJ: The stimulussecretion coupling of glucose-induced insulin release. XX. Fasting: a model for altered glucose recognition by the B-cell. Metabolism 25: 583-591, 1976.

35. Malaisse WJ, Sener A and Levy J: The stimulus-secretion coupling of glucose-induced insulin release. Fasting-induced adaptation of key glycolytic enzymes in isolated islets. J Biol Chem 251: 1731-1737, 1976. 